\title{
Mini-Chromosome Maintenance Protein Family: Novel Proliferative Markers - The Pathophysiologic Role and Clinical Application
}

\author{
Shirin Karimi ${ }^{1}$ and Makan Sadr ${ }^{2}$ \\ ${ }^{1}$ Shahid Beheshti University of Medical Science \\ ${ }^{2}$ Faculty of Medicine, Tehran University of Medical Science, Tehran,
}

Iran

\section{Introduction}

Proliferation markers are among the most important biologic markers in the pathogenesis of many benign and malignant tumoral lesions and also some non-neoplastic diseases. Extensive studies have been conducted on this matter shedding light on the role of these markers in the pathogenesis of many of these lesions and their contribution to standard diagnostic protocols, determination of prognosis and even treatment monitoring of diseased cases.

Cancer is among the major causes of morbidity and mortality worldwide. Determination and recognition of biomarkers that detect cancer in its early stages, monitor the disease progression or work as a specific marker for disease prognosis can boost our ability in confronting such conditions and improve cancer patients' care by creating a personalized medicine for them. Assessment of the cell growth or proliferative signature of tumoral lesions is among the main parameters in recognition of the biologic course of cancer, prognosis and evaluation of the treatment course.

At present, we focus on recently introduced proliferative markers; MCM protein family, their basic biologic role and short review of the clinical application.

\section{Cell cycle and proliferative markers}

Cell proliferation is a precisely supervised process initiated and controlled by a large number of molecules and interrelated pathways. Cell proliferation is induced and started by the act of growth factors. A controlled sequence of events take place sequentially for duplication and division of cell DNA during a process called cell cycle. The cell cycle consists of four distinct phases: $G_{1}$ phase (pre-synthetic), $S$ phase (DNA synthesis), $G_{2}$ phase (premyotic) and M phase (mitosis). Quiescent phase or G0 is a resting phase where the cell has left the cycle and has stopped dividing (1). Replication of the genomic DNA should be completed before the onset of mitosis and is performed once in every cell cycle.

Diagram of the cell cycle: 


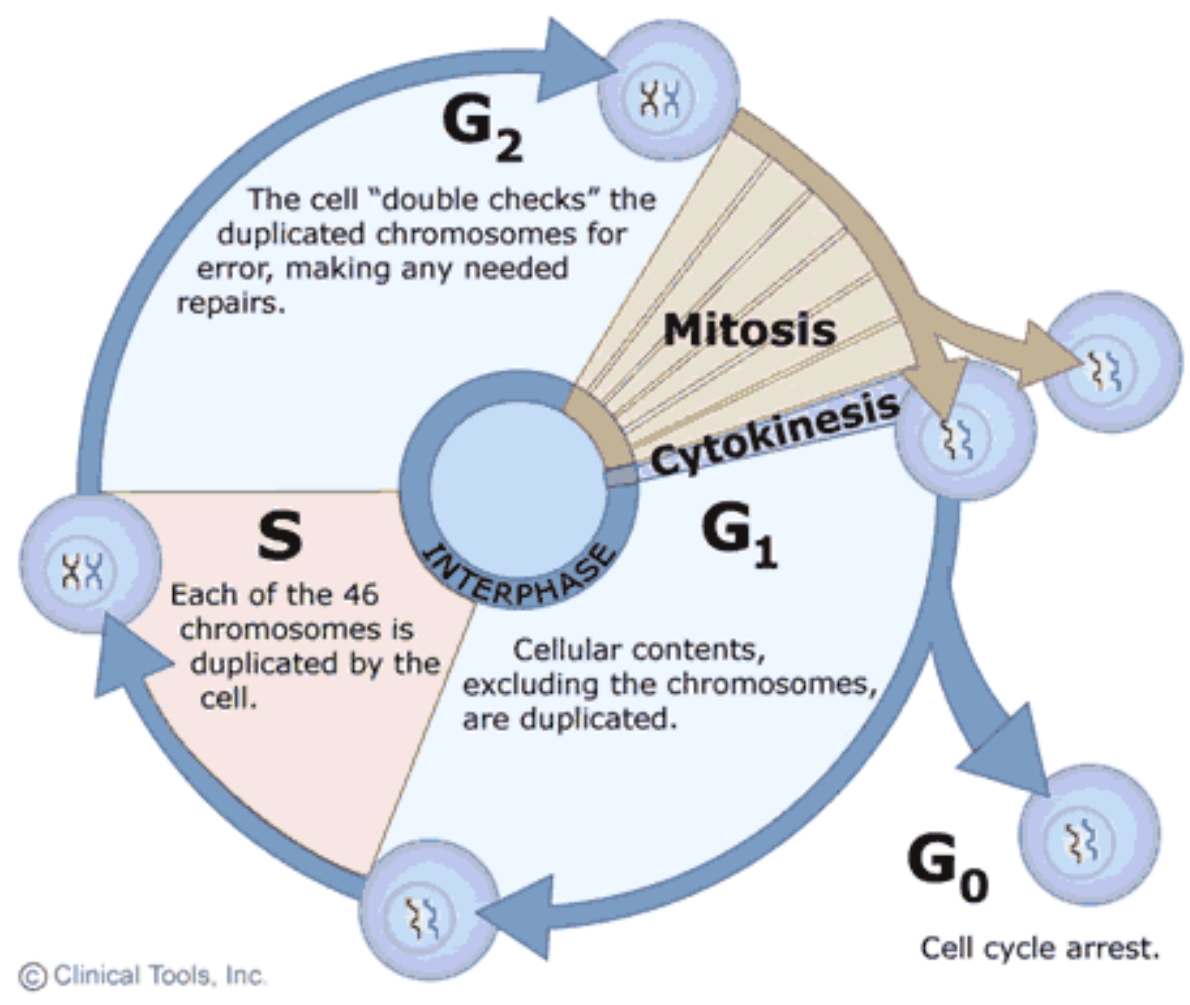

Several antigens are expressed during a cell cycle the oldest of which being Ki67 antigen. Some important antigens related to cell cycle were discovered later including PCNA, KiS2 and MCM.

Ki67 antigen was discovered by a German group of scientists (2) in early 1980s and identified by using mice monoclonal antibodies against a nuclear antigen from Hodgkin's lymphoma cell line. This antigen is a non-histone protein. The name is derived from the city of origin (Kiel, Germany) and the number of the original clone in the 96-well plate (2). Ki67 antigen has different expressions during various phases of cell cycle. Cells express this antigen in G1, S, G2 and M phases but they lack it in G0 phase. Concentration of Ki67 is low in G1 phase and reaches its peak during S phase. Ki67 is down-regulated during anaphase and telophase. Various studies on cell cycle analysis have shown that Ki67 antigen is not expressed in early G1 phase. Several antibodies are routinely being used for detection of Ki67 in paraffin embedded tissue samples using immunohistochemistry. At present, Ki67 index score is routinely employed showing tumoral cells exhibiting nuclear staining. Use of Ki67 as a diagnostic and prognostic marker in many neoplasms has been extensively studied and its role in standard biological evaluation of the clinical course and management of cancers among them Lymphomas and breast cancers has been well recognized (3-6).

MCM and cell cycle:

Numerous proteins have been recognized to play a role in initiation of DNA replication which mainly include Origin Recognition Complex (ORC) and MCMs (7). Prokaryotes lack 
MCM proteins and only eukaryotes possess this special type of molecules. However, some related proteins have been found in some prokaryotes like Archaea (8-10).

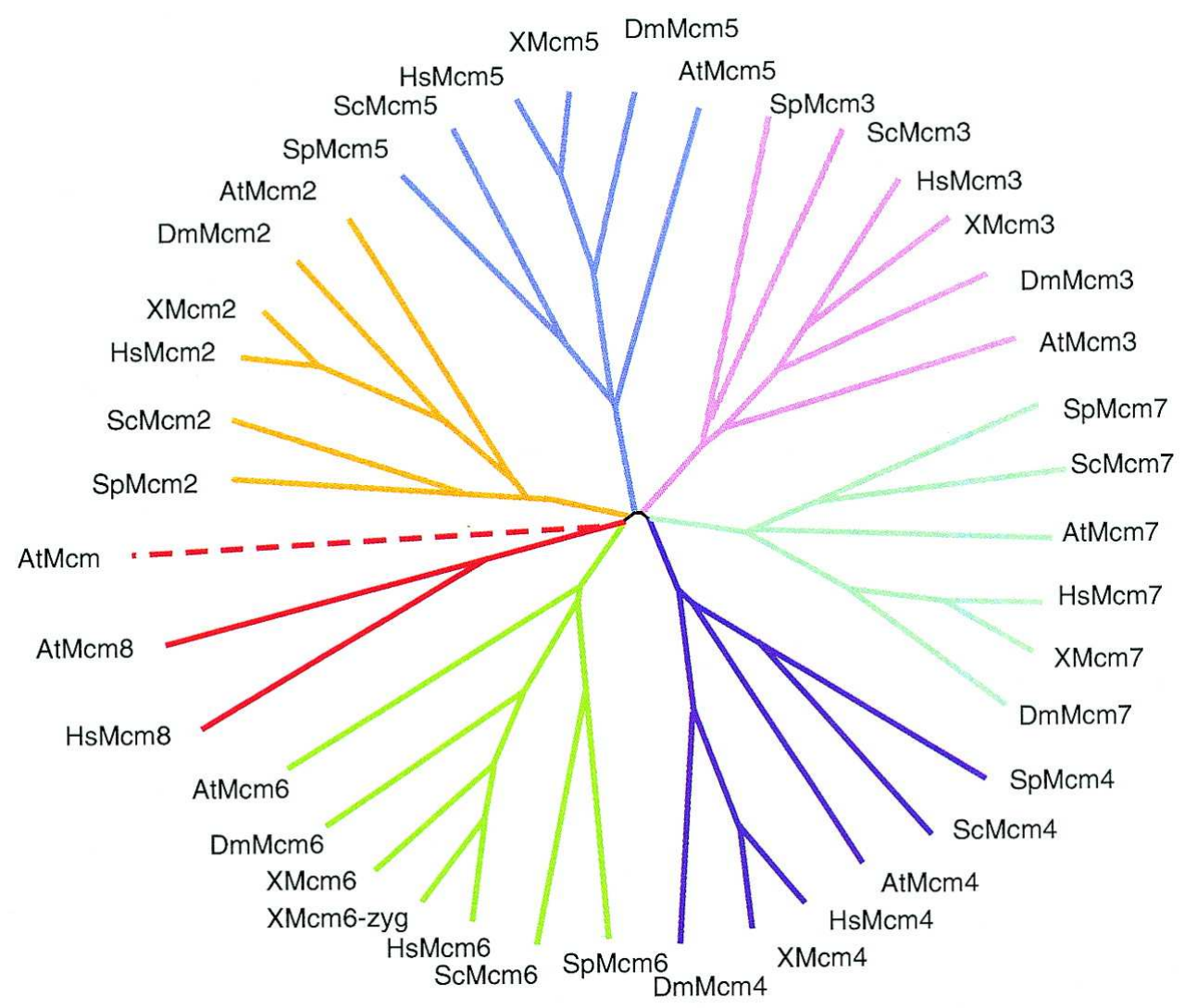

Fig. 1. Phylogenetic tree of eukaryotic MCMs, assembled using ClustalX (ftp://ftp-igbmc.ustrasbg.fr/pub/ClustalX/) and Phylip 3.6

(http:/ / evolution.genetics.washington.edu/phylip.html) for Macintosh. Colors correspond to the seven MCM subfamilies. Dashed line, loose relationship. Accession numbers are as follows. S. pombe: SpMcm2, CAB58403; SpMcm3, P30666; SpMcm4, P29458, SpMcm5, CAA93299 and CAB61472; SpMcm6, CAB75412; SpMcm7, O75001. S. cerevisiae: ScMcm2, NP_009530; ScMcm3, NP_010882; ScMcm4, S56050; ScMcm5, A39631; ScMcm6, NP_011314; ScMcm7, S34027. Human: HsMcm2, P49736; HsMcm3, P25205; HsMcm4, NP_005905; HsMcm5, AAH03656; HsMcm6, NP_005906; HsMcm7, P33993; HsMcm8, NP_115874. Xenopus: Xmcm2, JC5085; Xmcm3, I51685; Xmcm4, T47223; Xmcm5, PC4225; Xmcm6Z, AAC41267; Xmcm6, T47222; Xmcm7, T47221. Arabidopsis: AtMcm2, NP_175112.1; AtMcm3, NP_199440.1; AtMcm4, NP_179236.2; AtMcm5, NP_178812.1; AtMcm6, NP_680393.1; AtMcm7, NP_192115.1; AtMcm8?, NP_187577.1; unknown Mcm, NP_179021.1. Drosophila: DmMcm2, AAF54207; DmMcm3, NP_511048.2; DmMcm4, S59872; DmMcm5, NP_524308.2; DmMcm6, NP_511065.1; DmMcm7, NP_523984.1. [11] 
MCM proteins were first recognized in early 1980's in Bik-Kwoon laboratory because of their role in maintenance of plasmids and mini chromosomes in Saccharomycess Cervisiae proliferative cells (11).

The MCM protein family is named for the genetic screen in budding yeast from which the founding members were originally isolated. They were defective in minichromosome maintenance, showing a high rate of loss of plasmids that contained a cloned centromere and replication origin $[12,13]$.

These proteins play a role in the formation of prereplicative complex in G1 phase. By doing so, they license the chromatin for replication in the next phase of S (14).

The MCM family of proteins is considered the key factor for initiation of replication regulation through cyclical DNA unwinding (14). Also, they play a role in condensation, cohesion, transcription and recombination (11). These proteins mainly include 6 major groups of MCM2 to MCM7 (11). In addition, 4 proteins of this family have been recognized to have independent function from the previously mentioned group including MCM1, MCM10, MCM8 and MCM9. It seems that the latter group of proteins only exists in multicellular organisms and higher eukaryotes.

Although MCM1 and MCM10 belong to this family name wise, they do not have much in common with MCM2-MCM7. MCM1 is a transcription factor and does not have a direct role in DNA replication $(15,16)$.

MCM10 associates with MCM2-7 hexamer in the active replisome and helps to stabilize DNA polymerase $\alpha$-primase [Reviewed in 17].

MCM8 has been reported in vertebrates and Drosophila, but not in fungi and nematodes, and although it retains some sequence similarities in the Walker B and R-finger, its Walker A ATPase motif contains sequences more like the canonical ATPases. [18] Intriguingly, while human MCM8 shares all the classic MCM features including a putative zinc finger and the IDEKFM and arginine finger motifs, it is the only MCM that has a classic GKS motif in its Walker A sequence. It is widely expressed in a variety of tissues and may not be restricted to proliferating cells $[19,20]$. The protein is found in the nucleus, apparently chromatin associated during $S$ phase [19].

MCM9 is also found in similar organisms with the exception that it is missing in Drosophila, and it is unique to the family in that it lacks the carboxy-terminal ATPase domain including the Walker B motif. [18] MCM9 mRNA was up-regulated by transcription factor E2E1 and serum stimulation in NIH3T3 cells [21].

Various members of this family have been studied in all eukaryotes by genetic and biochemical methods and it has been demonstrated that MCM2-MCM7 proteins have been present in the genome of all the studied eukaryotes and have not been subject to gene loss or functional replacement during evolutionary diversification of eukaryotes.

In Drosophila, MCM4 corresponds to the gene disc proliferation abnormal [22], while in Arabidopsis, MCM7 is PROLIFERA [23], stressing their role in cell division. Human MCM2 (BM28) was first identified as a nuclear protein [24], and human MCM3 (P1) was isolated as a DNA polymerase alpha-associated protein [25].

Unusual MCMs

Unusual MCMs have been recognized during the course of various studies. For example, at present it has been found that some yeasts possess MCM6. However, some variants i.e. the zygotic form of MCM6 have been detected in Xenopus. Also, some variants of MCM4 have also been found (26). It seems that these variants are a substitute for normal MCM when adequate growth conditions are met. 


\section{DNA replication and MCM2-7 family proteins}

Prior to DNA replication and during late M and G1 phases of the cell cycle, MCM2-7 form the pre-replication complex (pre-RC) by being loaded on to the origin recognition complex $(\mathrm{ORC})$ at the origin of replication. This is activated at the G1-S transition of the cell cycle by the assembly of further protein components. [27] Only MCM2 and MCM3 have identifiable nuclear localization sequences (NLS), leading to an early suggestion that these MCMs provide nuclear targeting to the other members of the family [28]. In nearly all species, the bulk of MCMs are constitutively located in the nucleus throughout the entire cell cycle, with their chromatin association, rather than nuclear localization, subject to cell cycle regulation [24, 29-37]. However, there is still a role for the nuclear envelope in MCM complex assembly. This has been molecularly characterized using mutational analysis with the yeasts.

MCM core is a trimeric complex that forms during purification in result of binding MCM4, MCM6, and MCM7 subunits tightly together. MCM2 binds to the core, but with decreased affinity. MCM3 and MCM5 form a dimer together and bind most weakly to the other MCMs, probably through MCM7 (Figure 2). [11] In the absence of other MCMs during in vitro reconstitution experiments, the MCM4,6,7 core will itself dimerize to form a dimertrimer (MCM4,6,7)2, which is disrupted by addition of MCM2 [38-40].

All MCM members belong to the AAA+ ATPase family, which has a distinct ATPase domain that spans $\sim 200$ bases. This domain, referred to as the MCM box, consists of a Walker A ATPase motif, a Walker B ATPase motif, and an arginine finger motif (R-finger). Conserved sequences within the Walker B motif (IDEFDKM) and R-finger (SRDF) define the MCM family. Six of these members are conserved in all eukaryotes and form a heterohexameric complex known as MCM2-7, which has been studied extensively for its role in DNA replication. MCM2-7 is required for licensing and initiating origins of replication, and it acts during elongation as a helicase at the replication forks. Because of this function and studies in yeast, Arabidopsis and Drosophila, members of the MCM2-7 complex, are thought to be essential [41].

The assessment of other multiple functions is consistent with studies in yeast, which showed that MCM proteins are far more abundant than would likely be required for the number of replication origins that exist, and this abundance cannot explain the fact that slight decreases in amounts of MCM proteins lead to the inability to complete S-phase and progress through the cell cycle [41].

Early data led to the identification of MCMs as central players in the initiation of DNA replication. More recent studies have shown that MCM proteins also function in replication elongation, probably as a DNA helicase. This is consistent with structural analysis showing that the proteins interact together in a heterohexameric ring. However, MCMs are strikingly abundant and far exceed the stoichiometry of replication origins; they are widely distributed on unreplicated chromatin. Analysis of MCM mutant phenotypes and interactions with other factors has now implicated the MCM proteins in other chromosome transactions including damage response, transcription, and chromatin structure. These experiments indicate that the MCMs are central players in many aspects of genome stability [11]. This family of proteins has been studied for interaction with other genes like Rb gene.

\section{MCM gene expression, DNA replication and Retinoblastoma gene}

Model showing RBR3 role in the RBR/E2F pathway controlling the expression of MCM2-7 genes, DNA replication, and cell transformation. RepA inhibits RBR1; thus, stimulating the 
pathway leading to S-phase gene expression, DNA synthesis, and cell transformation through up-regulation of RBR3. The transgenic approaches to down- or up-regulate RBR3 are indicated in italics. The dotted line illustrates a potential inhibitory effect of RepA on RBR3 ruled out by Sabelli et al work[42].

Fig. 3.

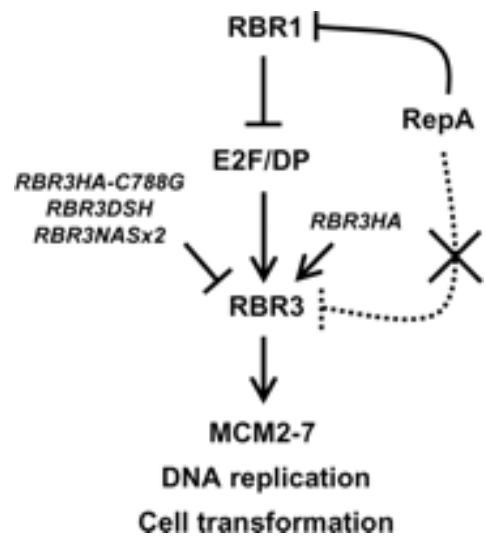

\section{Expression of MCM protein family as a biological marker of proliferation in various diseases}

Genome of the MCM family is necessary for DNA replication and its role has been studied in various diseases and cancers. After the conduction of aforementioned basic studies, it was quickly revealed that this family of proteins not only can be considered as a cell proliferation marker but also can out-power previous classic factors of proliferation such as Ki67 because MCM expression in all phases of cell cycle.

Parvaresh and colleagues (7) through cytometer analysis showed that number of cells expressing MCM6 in the proliferation phase was higher than those expressing Ki67 which was due to the expression of MCM6 at early G1 phase, a phase of cell cycle which does not express Ki67 antigen. This study suggested that MCM6 may be a unique marker of cell cycle and might be employed as a novel prognostic marker for management of cancers.

The following is the summary of studies on different members of this family:

\section{Clinicopathologic studies on expression of MCM family proteins as proliferative markers}

\subsection{Expression of MCM family proteins in non neoplastic diseases}

DNA synthesis disorders and DNA damage response can also be important in pathogenesis of many non-neoplastic diseases. Since MCM family proteins play a major role in initiation of DNA synthesis and DNA damage response, evaluation of MCM subunits can be effective in recognizing the cause of various non neoplastic diseases.

Cortez and colleagues showed that 2 MCM subunits namely MCM2-3 and MCM7 can be used as a check point for $S$ phase considering their correlation with Ataxia-telangiectasia mutated (ATM) and ATM- and Rad3-related (ATR) and ATR-interacting protein (ATRIP)interacting subunit (43). 
Evaluation of these factors has also helped in pathogenesis of Diabetes and some viral diseases.

Willcox and coworkers (45) demonstrated that in type I diabetes Alpha and Beta cells undergo an increase in proliferation during progression. These cells show a high level of coexpression of Ki67 and MCM which are indicative of a proliferative response in an autoimmune attack during the course of diabetes type I.

Qian and colleagues (44) showed that MCM complex can be effective in understanding the pathogenesis of many viral diseases. Targeting MCM complex is one mechanism pUL117 employs to help block cellular DNA synthesis during HCMV infection. Their finding substantiates an emerging picture that deregulation of $\mathrm{MCM}$ is a conserved strategy for many viruses to prevent host DNA synthesis and helps to elucidate the complex strategy used by a large DNA virus to moderate cellular processes to promote infection and pathogenesis.

\subsection{Role of MCM family proteins in neoplastic lesions}

Since classically proliferative biomarkers like Ki67 and proliferating cell nuclear antigen (PCNA) are known as the indices of proliferation phase, they are extensively used as diagnostic biomarkers in many types of cancers.

Recently, MCM family proteins are a group of proteins that has been described in DNA replication in both benign and malignant tumors. As MCM proteins are only recognizable in cells which are in the cell cycle, therefore, it seems that they could be a better indicator of proliferative cells, cancer cells or malignant tissues compared to conventional biomarkers. Numerous studies has been suggested that their expression in some of the preneoplastic lesions and malignancies is often associated with a higher degree of cell atypia and poor prognosis.

Up to our knowledge, expression of MCM family proteins has been extensively studied in neoplastic disorders including skin tumors, meningioma, non-small cell lung cancer, Hodgkin's lymphoma [47], prostate cancer, oral tongue squamous cell carcinoma [48], chondrosarcoma, oligodendroglial tumors, esophageal neoplasm, renal cell carcinoma, colonic cancer, breast cancer, endometrial carcinoma, thyroid carcinoma, gastric adenocarcinoma, merckle cell carcinoma, cervical carcinoma and bladder carcinoma. A summary of these studies is as follows:

- Among skin tumors, squamous cell carcinoma, Bowen disease, basal cell carcinoma, malignant melanoma, and nevus have been studied (46). Also, Shin et al. reported a significant positive correlation between MCM2 immunoactivity and grade of actinic keratosis. They declared MCM2 as a reliable marker for diagnosis and grading and suggested further investigation on its prognostic value.

- Shahjahan and associates [49] studied ProEx C, a biomarker reagent containing antibodies to minichromosome maintenance protein 2 (MCM2) and topoisomerase II A (TOP2A) used to detect aberrant S-phase induction in cells. The authors studied 289 non-small cell lung cancers using immunohistochemistry and found ProEx C expression in more than two-thirds of the cancers and an association between strong expression and a longer 5-year survival in certain cellular subtypes. The findings suggested a role in tumor progression of these cancer cells and might be a potential basis for targeted therapy. 
- Histomorphology and immunohistochemistry studies also showed increased expression of MCM2 in areas of malignant transformation in recurrent pleomorphic adenoma (50).

- Nuclear expression of MCM2 has been demonstrated in a large number of breast cancer patients. Its expression in dysplastic, malignant and cancer cells can be predictive of potential malignancy and can help in determining the grade of breast cancer $(51,52)$.

- Expression of MCM3 has been evaluated in astrocytic tumors and cervical carcinoma (53).

- High expression of MCM4 has been reported in meningioma and cervical carcinoma $(52,54)$.

- Also, MCM4 may play an essential role in the proliferation of some NSCLC cells. Taken together with higher expression in NSCLCs and its correlation with clinicopathologic characteristics such as non-adenocarcinoma histology, MCM4 may have potential as a therapeutic target in certain population with NSCLCs [55, 56].

- Increased expression of MCM4 might be associated with pathological staging of esophageal cancer [57].

- MCM5 expression has been shown in hepatitis induced carcinogenesis (58), adenocarcinoma of the stomach (59), and meningioma (60). Co-expression of MCM2 and MCM5 as a marker of proliferation and differentiation has been evaluated in colon cancer. High expression of these two in mild and moderate cutaneous dysplasia in proliferative lesions of verrucous leukoplakia can help in studying the prognosis of their malignant transformation. Despite the expression of MCM4 and MCM5, increased expression of MCM6 and MCM7 has also been studied in meningioma (54).

- A study showed that expression of MCM7 in esophageal squamous cell carcinoma was associated with a more invasive nature (61).

- Aberrant over-expression of proteins called minichromosome maintenance (MCM) proteins at the mucosal surface of dysplastic esophageal squamous epithelium and Barrett's mucosa may indicate proliferation potential. [62]

- MCM7 detected more cells in the cycle than Ki67 and PCNA and all cases of SC glioblastoma, the most aggressive subset, displayed a significant increase of MCM7stained nuclei versus those stained with Ki67. [63] These studies implicate MCM7, and the DNA replication licensing gene family, in prostate cancer progression, growth and invasion. [64] MCM-7 also has been studied in gestational trophoblastic disease [65] and metastatic colon carcinoma [66].

- In previous studies such as in Fujioka et al [67] study they demonstrated that higher levels of MCM 7 expression were correlated with poor differentiation of tumors, nonbronchioloalveolar carcinomas of lung, large tumor size and poor prognosis. Li et al [68] also showed that MCM 7 expression was significantly correlated with poor histologic grade, old age, and poor survival in cases of endometrial carcinoma. Padmanabhan et al [69] revealed that MCM 7 was associated with tumor stage and perineural invasion in prostatic intraepithelial neoplasia and invasive adenocarcinoma.

\subsection{The role of MCM protein family in cancer treatment}

Because of MCM family proteins' vital role in genome duplication in proliferating cells, deregulation of the MCM function results in chromosomal defects that may contribute to tumorigenesis. As we already reviewed, the MCM proteins are highly expressed in 
malignant human cancers cell and pre-cancerous cells undergoing malignant transformation. They are not expressed in differentiated somatic cells that have been withdrawn from the cell cycle. Therefore, these proteins are ideal diagnostic markers for cancer and promising targets for anti-cancer drug development. [70)

In this respect, medications targeting some members of the MCM family are considered novel anticancer drugs.

Two studies evaluated the role of medications in management of the tumor in prostate cancer patients by measuring the expression of MCMs. In one of these studies due to the high level of MCM expression in these lesions Genistein and Trichostatin (TSA) were administered resulting in down-regulation of all MCM genes and subsequently decreasing the $S$ phase in tumoral cells of the prostate cancer (54).

Iljin et al, (71) in their study indicated that three novel cancer selective growth inhibitory compounds can result in decreased DNA synthesis. This reduction can be evaluated via MCM expression.

\section{Conclusion}

Members of the MCM family play a key role as the initiator of DNA replication working as DNA helicase. They are also involved in the process of transcription, cohesion, condensation, and recombination in both the nucleus and the cytoplasm. These markers have been extensively evaluated in basic and clinical studies. Aforementioned clinical studies showed the expression of these proteins specially MCM 2, 3,4,5,6,7 specially in preneoplastic and cancers and also in some viral and endocrine diseases eg Diabetes . They have been suggested as standard diagnostic and prognostic biomarkers in some tumoral lesions.

Many of these proteins can be employed as a target for anti-cancer medications currently present in the market or those under development.

Further studies on various members of this family in all the pathologic diseases specially precancerous lesions and malignant processes can illuminate their pathogenesis and biologic behavior. In tumoral lesions, these markers can be easily evaluated through immunohistochemistry. Therefore, it is recommended that research projects focus on studying not only one of them but evaluation co expression of some of the various members of this family in tumoral, pre-neoplastic and neoplastic lesions in all organs.In this way, these proliferative markers can gradually substitute the standard proliferative index markers like Ki67 which was the main objective of the present review.

\section{References}

[1] Kumar V, Abbas A, Fausto N, Aster J C. Pathologic Basis of Disease $8^{\text {th }}$ ed. Philadelphia, PA: Saunders/Elsevier, 2010; p266-267.

[2] Gerdes J, Schwab U, Lemke H, Stein H. Production of a mouse monoclonal antibody reactive with a human nuclear antigen associated with cell proliferation. Int J Cancer 1983;31:13-20.

[3] Dai H, vant Veer L, Lamb J et al. A cell proliferation signature is a marker of extremely poor outcome in a subpopulation of breast cancer patients. Cancer Res 2005; 65: 4059-66. 
[4] Bonnefoi H, Underhill C, Iggo R, Cameron D. Predictive signatures for chemotherapy sensitivity in breast cancer: are they ready for use in the clinic? Eur J Cancer 2009; 45: 1733-43.

[5] Whitfield ML, George LK, Grant GD et al. Common markers of proliferation. Nat Rev Cancer 2006; 6: 99-106.

[6] Kreipe H, Wacker H H, Heidebrecht H J, Haas K, Hauberg M, Tiemann M, Parwaresch R. Determination of the growth fraction in non-Hodgkin's lymphomas by monoclonal antibody Ki-S5 directed against a formalin-resistant epitope of the Ki67 antigen. Am J Pathol 1993;142(6): 1689-94.

[7] Heidebrecht H J, Buck F, Endl E, Kruse M L, Adam-Klages S, Andersen K, Frahm S O, Schulte C, Wacker H H, Parwaresch R. Ki-Mcm6, a new monoclonal antibody specific to MCM6: Comparison of the distribution profile of MCM6 and the Ki67 antigen. Laboratory Investigation 2001; 81: 1163-65.

[8] Kearsey, S. E., and K. Labib. MCM proteins: evolution, properties, and role in DNA replication. Biochim. Biophys. Acta 1998;1398:113-136.

[9] Kelman, Z., and J. Hurwitz. Structural lessons in DNA replication from the third domain of life. Nat. Struct. Biol. 2003;10:148-150.

[10] Tye, B. K. Insights into DNA replication from the third domain of life. Proc. Natl. Acad. Sci. USA 2000; 97:2399-2401.

[11] Forsburg S L. Eukaryotic MCM proteins: Beyond Replication Initiation. Molecular \& Cell Biology Laboratory, The Salk Institute for Biological Studies, La Jolla, California 92037.

[12] Maine, G. T., P. Sinha, and B.-K. Tye. Mutants of S. cerevisiae defective in the maintenance of minichromosomes. Genetics 1984; 106:365-385.

[13] Sinha, P., V. Chang, and B.-K. Tye. A mutant that affects the function of autonomously replicating sequences in yeast. J. Mol. Biol. 1986; 192:805-814.

[14] Burger M. MCM2 and MCM5 as Prognostic Markers in Colon Cancer: A Worthwhile Approach. Dig Dis Sci 2009; 54: 197-8.

[15] Passmore S, Elble R, Tye BK. A protein involved in minichromosome maintenance in yeast binds a transcriptional enhancer conserved in eukaryotes. Genes Dev 1989; 3: 921-35.

[16] Christ C, Tye BK. Functional domains of the yeast transcription/replication factor MCM1. Genes Dev 1991; 5: 751-63.

[17] Moore K, Aves SJ. MCM10 and DNA replication in fission yeast. In: The Eukaryotic cell cycle. Edited by: Bryant JA, Francis D. Abingdon: Taylor and Francis; 2008: 4569.

[18] Lake C. M., Teeter K., Page S. L., Nielsen R. and Hawley R. S. A genetic analysis of the Drosophila mcm5 gene defines a domain specifically required for meiotic recombination. Genetics 2007; 176(4): 2151-63.

[19] Gozuacik, D., M. Chami, D. Lagorce, J. Faivre, Y. Murakami, O. Poch, E. Biermann, R. Knippers, C. Brechot, and P. Paterlini-Brechot. Identification and functional characterization of a new member of the human Mcm protein family: hMcm8. Nucleic Acids Res. 2003; 31:570-579.

[20] Johnson, E. M., Y. Kinoshita, and D. C. Daniel. A new member of the MCM protein family encoded by the human MCM8 gene, located contrapodal to GCD10 at chromosome band 20p12.3-13. Nucleic Acids Res. 2003; 31:2915-2925. 
[21] Yoshida K. Identification of a novel cell-cycle-induced MCM family protein MCM9. Biochemical and Biophysical Research Communications 2005; 331(2): 669-74.

[22] Feger, G., H. Vaessin, T. T. Su, E. Wolff, L. Y. Jan, and Y. N. Jan. dpa, a member of the MCM family, is required for mitotic DNA replication but not endoreplication in Drosophila. EMBO J. 1995; 14:5387-5398.

[23] Springer, P. S., W. R. McCombie, V. Sundaresan, and R. A. Martienssen. Gene trap tagging of PROLIFERA, and essential MCM2-3-5 like gene in Arabidopsis. Science $1995 ; 268: 877-880$.

[24] Todorov, I. T., R. Pepperkok, R. Philipova, S. E. Kearsey, W. Ansorge, and D. Werner. A human nuclear protein with sequence homology to a family of early $S$ phase proteins is required for entry into S phase and for cell division. J. Cell Sci. 1994; 107:253-265.

[25] Thömmes, P., R. Fett, B. Schray, R. Burkhart, M. Barnes, C. Kennedy, N. C. Brown, and R. Knippers. Properties of the nuclear P1 protein, a mammalian homologue of the yeast MCM3 replication protein. Nucleic Acids Res. 1992; 20:1069-1074.

[26] Sible, J. C., E. Erikson, M. Hendrickson, J. L. Maller, and J. Gautier. Developmental regulation of MCM replication factors in Xenopus laevis. Curr. Biol. 1998; 8:347-350.

[27] Liu Y, Richards T A, Aves S J. Ancient diversification of eukaryotic MCM DNA replication proteins. BMC Evolutionary Biology 2009; 9:60. doi:10.1186/1471-21489-60.

[28] Kimura, H., T. Ohtomo, M. Yamaguchi, A. Ishii, and K. Sugimoto. Mouse MCM proteins: complex formation and transportation into the nucleus. Genes Cells 1996; 1:977-993.

[29] Fujita, M., T. Kiyono, Y. Hayashi, and M. Ishibashi. Hcdc47, a human member of the MCM family-dissociation of the nucleus-bound form during $S$ phase. J. Biol. Chem. 1996; 271:4349-4354.

[30] Hu, B., R. Burkhart, D. Schulte, C. Musahl, and R. Knippers. The P1 family-a new class of nuclear mammalian proteins related to the yeast MCM replication proteins. Nucleic Acids Res. 1993; 21:5289-5293.

[31] Kearsey, S. E., S. Montgomery, K. Labib, and K. Linder. Chromatin binding of the fission yeast replication factor Mcm4 occurs during anaphase and requires ORC and Cdc18. EMBO J. 2000; 19:1681-1690.

[32] Kimura, H., N. Nozaki, and K. Sugimoto. DNA polymerase alpha associated protein P1, a murine homolog of yeast $M C M 3$, changes its intranuclear distribution during the DNA synthetic period. EMBO J. 1994; 13:4311-4320.

[33] Madine, M. A., C. Y. Khoo, A. D. Mills, C. Musahl, and R. A. Laskey. The nuclear envelope prevents reinitiation of replication by regulating the binding of $\mathrm{Mcm} 3$ to chromatin in Xenopus egg extracts. Curr. Biol. 1995; 5:1270-1279.

[34] Okishio, N., Y. Adachi, and M. Yanagida. Fission yeast nda1 and nda4, MCM homologs required for DNA replication, are constitutive nuclear proteins. J. Cell Sci. 1996; 109:319-326.

[35] Pasion, S. G., and S. L. Forsburg. Nuclear localization of Schizosaccharomyces pombe Mcm2/Cdc19p requires MCM complex assembly. Mol. Biol. Cell 1999; 10:40434057.

[36] Schulte, D., R. Burkhart, C. Musahl, B. Hu, C. Schlatterer, H. Hameister, and R. Knippers. Expression, phosphorylation and nuclear localization of the human P1 
protein, a homoogue of the yeast Mcm 3 replication protein. J Cell Sci. 1995; 108:1381-1389.

[37] Su, T. T., and P. H. O'Farrell. Chromosome association of minichromosome maintenance proteins in Drosophila mitotic cycles. J. Cell Biol. 1997; 139:13- 21.

[38] Ishimi, Y. A DNA helicase activity is associated with an MCM4, -6, and -7 protein complex. J. Biol. Chem 1997;272:24508-24513.

[39] Lee J K and Hurwitz J. Isolation and characterization of various complexes of the minichromosome maintenance proteins of Schizosaccharomyces pombe. J. Biol. Chem. $2000 ; 275: 18871-18878$.

[40] Prokhorova, T. A., and J. J. Blow. Sequential MCM/P1 subcomplex assembly is required to form a heterohexamer with replication licensing activity. J. Biol. Chem. 2000; 275:2491-2498.

[41] Minichromosome maintenance 5. Biological overview. http://www.sdbonline.org/fly/genebrief/mcm5.htm

[42] Sabelli P A, Hoerster G, Lizarraga L E, Brown S W, Gordon-Kamm W J, Larkins B A. Positive regulation of minichromosome maintenance gene expression, DNA replication, and cell transformation by a plant retinoblastoma gene. PNAS 2009; 106(10):4042-47.

[43] Shechter D, Gautier J. MCM proteins and checkpoint kinases get together at the fork. http://www.pnas.org/content/101/30/10845.full

[44] Qian Zh, Leung-Pineda V, Xuan B, Piwnica-Worms H, Yu D. Human cytomegalovirus protein pUL117 targets the mini-chromosome maintenance complex and suppresses cellular DNA synthesis. PLoS Pathogens 2010;6(3):1-14 (e1000814).

[45] Willcox A, Richardson SJ, Bone AJ, Foulis AK, Morgan NG. Evidence of increased islet cell proliferation in patients with recent-onset type 1 diabetes.Diabetologia 2010;53(9):2020-8.

[46] Shin JW, Kim Y K, Cho K H. Minichromosome maintenance protein expression according to the grade of atypism in actinic keratosis. Am J Dermatopathology 2010;32:794-8.

[47] Karimi Sh, Mohammadi F, Khodadad K, Emami H, Seyfollahi L. High Expression of Minichromosome Maintenance Protein 6 in Classic Hodgkin's Lymphoma Points to a Cell Cycle Arrest in G1 Phase. Archives of Iranian Medicin 2008; 11(5): 532 - 538.

[48] Gueiros LA, Coletta RD, Kowalski LP, Lopes MA. Clinicopathological features and proliferation markers in tongue squamous cell carcinomas. Int J Oral Maxillofacial Sur 2011.

[49] DABS D. Diagnostic immunohistochemistry: theranostic and genomic applications. 3rd ed. Philadelphia, PA: Saunders/Elsevier,2010;p412.

[50] Soares A B, Atemani A, De Araujo V C. Study of histopathological, morphological and immunohistochemical features of recurrent pleomorphic adenoma: an attempt to predict recurrence of pleomorphic adenoma. J Oral Pathol Med 2011;40:352-358.

[51] Wojnar A, Kobierzycki C, Krolicka A, Pula B, Podhorska-Okolow M, Dziegiel P. Correlation of Ki-67 and MCM-2 proliferative marker expression with grade of histological malignancy $(G)$ in ductal breast cancers. Folia Histochemica et Cytobiologica 2010;48(3):442-446. 
[52] Cobanoglu U, Mungan S, Gundogdu C, Ersoz S, Ozoran Y, Aydin F. The expression of MCM-2 in invasive breast carcinoma: a stereologic approach. Bratisl Lek Listy 2010; 111(1): 45-49.

[53] Söling A, Sackewitz M, Volkmar M, Schaarschmidt D, Jacob R, Holzhausen H R, Rainov N G. Minichromosome Maintenance Protein 3 Elicits a Cancer-Restricted Immune Response in Patients with Brain Malignancies and Is Strong Independent Predictor of Survival in Patients with Anaplastic Astrocytoma. Clinical Cancer Research 2005;11:249.

[54] Majid S, Dar AA, Saini S, Chen Y, Shahryari V, Liu J, Zaman MS, Hirata H, Yamamura S, Ueno K, Tanaka Y, Dahiya R. Regulation of Minichromosome Maintenance Gene Family by MicroRNA-1296 and Genistein in Prostate Cancer. Cancer Res 2010; 70(7): 2809-18.

[55] Kikuchi J, Kinoshita I, Shimizu Y, Kikuchi E, Takeda K, Aburatani H, Oizumi S, Konishi J, Kaga K, Matsuno Y, Birrer MJ, Nishimura M, Dosaka-Akita H. Minichromosome maintenance (MCM) protein 4 as a marker for proliferation and its clinical and clinicopathological significance in non-small cell lung cancer. Lung Cancer, Sep 2010.

[56] Kikuchia J, Kinoshitab I, Shimizub Y, Kikuchia E, Takedab K, Aburatanie H, Oizumia $\mathrm{S}$, et al. Proliferation marker and its clinical and clinicopathological significance in non small cell lung cancer. ??? 2011;72(2):229-237.

[57] Huang X P. Mcm4 Expression in Esophageal Cancer from Southern China and Its Clinical Significance. UICC World Cancer Congress 2006. Bridging the Gap: Transforming Knowledge into Action.July 8-12, 2006, Washington, DC, USAhttp://2006.confex.com/uicc/uicc/techprogram/P1872.HTM

[58] Qu A, Shah YM, Matsubara T, Yang Q, Gonzalez FJ. Pdent activation of cell cycle control and DNA repair genes in hepatic nonparenchymal cells. Toxicol Sci 2010;118(2):404-10.

[59] Giaginis C, Giagini A, Tsourouflis G, Gatzidou E, Agapitos E, Kouraklis G, Theocharis S. MCM-2 and MCM-5 expression in gastric adenocarcinoma: clinical significance and comparison with Ki-67 proliferative marker. Dig Dis Sci 2011;56(3):777-85.

[60] Saydam O, Senol O, Schaaij-Visser T B. M., Pham T V, Piersma S R, StemmerRachamimov A O, Wurdinger T, Saskia M. Peerdeman S M, and Jimenez C R. Comparative Protein Profiling Reveals Minichromosome Maintenance (MCM) Proteins As Novel Potential Tumor Markers for Meningiomas. J. Proteome Res 2010; 9(1): 485-494.

[61] Ahn J H \& Chang H K. (2010) Expression of Minichromosome Maintenance Protein 7 and Smad 4 in Squamous Cell Carcinoma of the Esophagus. Korean J Pathol 2010;44(4):346-353.

[62] Alison MR, Hunt T, Forbes SJ. Minichromosome maintenance (MCM) proteins may be pre-cancer markers. Gut 2002;50:290-291.

[63] Facoetti A, Ranza E, Benericetti E, Ceroni M, Tedeschi F \& Nano R. Minichromosome Maintenance Protein 7: A Reliable Tool for Glioblastoma Proliferation Index. Anticancer Research 2006; 26(2A): 1071-1075.

[64] Baoguo R, Guoying Y, George C. T, Kathleen C, George K. M, Joel N, Yan P. Y and Jian-Hua L. MCM7 amplification and overexpression are associated with prostate cancer progression. Amer Assoc Cancer Res 2006; 47. 
[65] Evrin C, Clarke P, Zech J, Lurz R, Sun J, Uhle S, Li H, Stillman B, Speck C. A doublehexameric MCM2-7 complex is loaded onto origin DNA during licensing of eukaryotic DNA replication. Proc Natl Acad Sci U S A. 2009;106(48):20240-5.

[66] Brewster AS, Slaymaker IM, Afif SA, Chen XS. Mutational analysis of an archaeal minichromosome maintenance protein exterior hairpin reveals critical residues for helicase activity and DNA binding. BMC Molecular Biology 2010, 11:62doi:10.1186/1471-2199-11-62

[67] Fujioka S, Shomori K, Nishihara K, et al. Expression of minichromosome maintenance 7 (MCM7) in small lung adenocarcinoma (pT1): prognostic implication. Lung Cancer 2009; 65: 223-9.

[68] Li SS, Xue WC, Khoo US, et al. Replicative MCM7 protein as a proliferation marker in endometrial carcinoma: a tissue microarray and clinicopathological analysis. Histopathology 2005; 46: 307-13.

[69] Padmanabhan V, Callas P, Philips G, Trainer TD, Beatty BG. DNA replication regulation protein $\mathrm{Mcm} 7$ as a marker of proliferation in prostatic cancer. J Clin Pathol 2004; 57: 1057-62.

[70] Lei M. The MCM complex: its role in DNA replication and implications for cancer therapy. Curr Cancer Drug Targets 2005;5(5):365-80.

[71] Iljin K, Ketola K, Vainio P, Halonen P, Kohonen P, Fey V et al. High-throughput cellbased screening of 4910 known drugs and drug-like small molecules identifies disulfiram as an inhibitor of prostate cancer cell growth. 


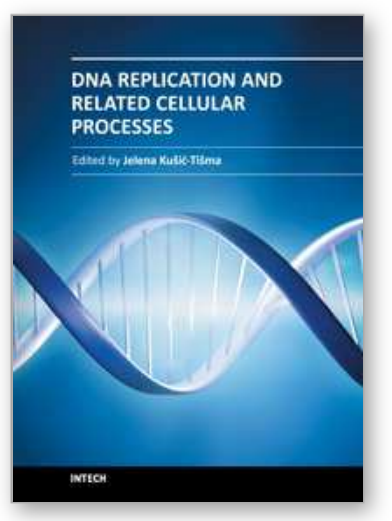

\section{DNA Replication and Related Cellular Processes}

Edited by Dr. Jelena Kusic-Tisma

ISBN 978-953-307-775-8

Hard cover, 300 pages

Publisher InTech

Published online 26, September, 2011

Published in print edition September, 2011

Since the discovery of the DNA structure researchers have been highly interested in the molecular basis of genome inheritance. This book covers a wide range of aspects and issues related to the field of DNA replication. The association between genome replication, repair and recombination is also addressed, as well as summaries of recent work of the replication cycles of prokaryotic and eukaryotic viruses. The reader will gain an overview of our current understanding of DNA replication and related cellular processes, and useful resources for further reading.

\section{How to reference}

In order to correctly reference this scholarly work, feel free to copy and paste the following:

Shirin Karimi and Makan Sadr (2011). Mini-Chromosome Maintenance Protein Family: Novel Proliferative Markers - The Pathophysiologic Role and Clinical Application, DNA Replication and Related Cellular Processes, Dr. Jelena Kusic-Tisma (Ed.), ISBN: 978-953-307-775-8, InTech, Available from: http://www.intechopen.com/books/dna-replication-and-related-cellular-processes/mini-chromosomemaintenance-protein-family-novel-proliferative-markers-the-pathophysiologic-role-and

\section{INTECH}

open science | open minds

\section{InTech Europe}

University Campus STeP Ri

Slavka Krautzeka 83/A

51000 Rijeka, Croatia

Phone: +385 (51) 770447

Fax: +385 (51) 686166

www.intechopen.com

\section{InTech China}

Unit 405, Office Block, Hotel Equatorial Shanghai

No.65, Yan An Road (West), Shanghai, 200040, China

中国上海市延安西路65号上海国际贵都大饭店办公楼 405 单元

Phone: +86-21-62489820

Fax: $+86-21-62489821$ 
(C) 2011 The Author(s). Licensee IntechOpen. This chapter is distributed under the terms of the Creative Commons Attribution-NonCommercialShareAlike-3.0 License, which permits use, distribution and reproduction for non-commercial purposes, provided the original is properly cited and derivative works building on this content are distributed under the same license. 